Corrigendum

\title{
Corrigendum to "Effect of Short-Term Stimulation with Interleukin-1 $\beta$ and Differentiation Medium on Human Mesenchymal Stromal Cell Paracrine Activity in Coculture with Osteoblasts"
}

\author{
Jan O. Voss, ${ }^{1,2}$ Claudia Loebel, ${ }^{1}$ Jennifer J. Bara, ${ }^{1}$ Marc Anton Fuessinger, ${ }^{1,3}$ \\ Fabian Duttenhoefer, ${ }^{3}$ Mauro Alini, ${ }^{1}$ and Martin J. Stoddart ${ }^{1}$ \\ ${ }^{1}$ AO Research Institute Davos, 7270 Davos Platz, Switzerland \\ ${ }^{2}$ Department of Oral and Maxillofacial Surgery/Clinical Navigation, Charité-Universitätsmedizin Berlin, \\ Campus Virchow-Clinic, 13353 Berlin, Germany \\ ${ }^{3}$ Department of Oral and Maxillofacial Surgery, Medical Center-University of Freiburg, 79106 Freiburg, Germany \\ Correspondence should be addressed to Martin J. Stoddart; martin.stoddart@aofoundation.org
}

Received 23 October 2016; Accepted 31 October 2016

Copyright (C) 2016 Jan O. Voss et al. This is an open access article distributed under the Creative Commons Attribution License, which permits unrestricted use, distribution, and reproduction in any medium, provided the original work is properly cited.

In the article titled "Effect of Short-Term Stimulation with Interleukin- $1 \beta$ and Differentiation Medium on Human Mesenchymal Stromal Cell Paracrine Activity in Coculture with Osteoblasts" [1], the last name of the fourth author was given incorrectly as Fussinger. The author's last name should have been written as Fuessinger. The revised authors' list is shown above.

\section{References}

[1] J. O. Voss, C. Loebel, J. J. Bara et al., "Effect of short-term stimulation with interleukin- $1 \beta$ and differentiation medium on human mesenchymal stromal cell paracrine activity in coculture with osteoblasts," BioMed Research International, vol. 2015, Article ID 714230, 16 pages, 2015. 


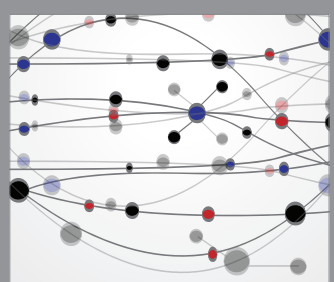

The Scientific World Journal
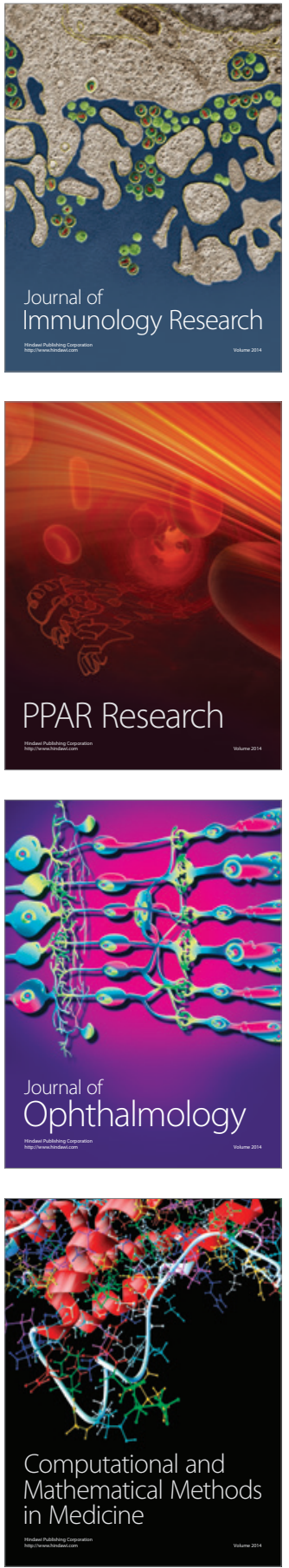

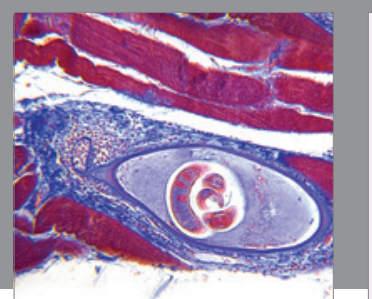

Gastroenterology Research and Practice

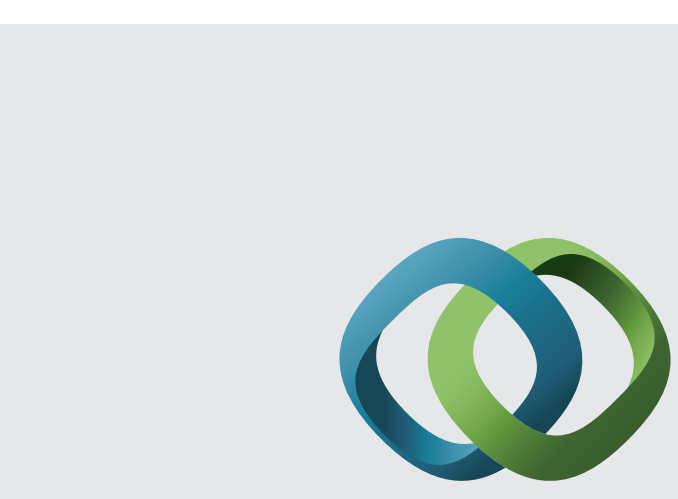

\section{Hindawi}

Submit your manuscripts at

http://www.hindawi.com
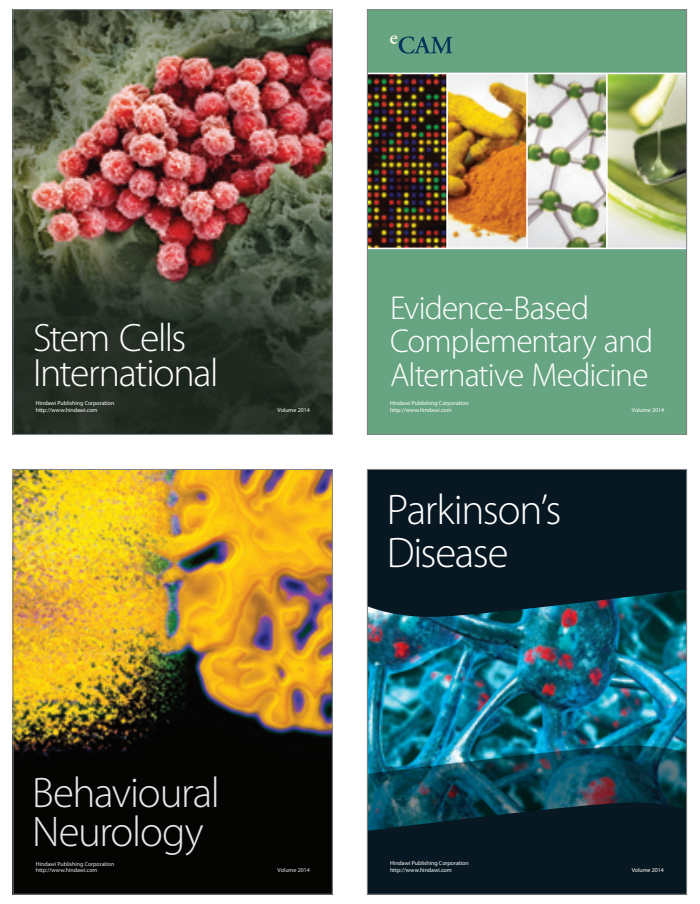
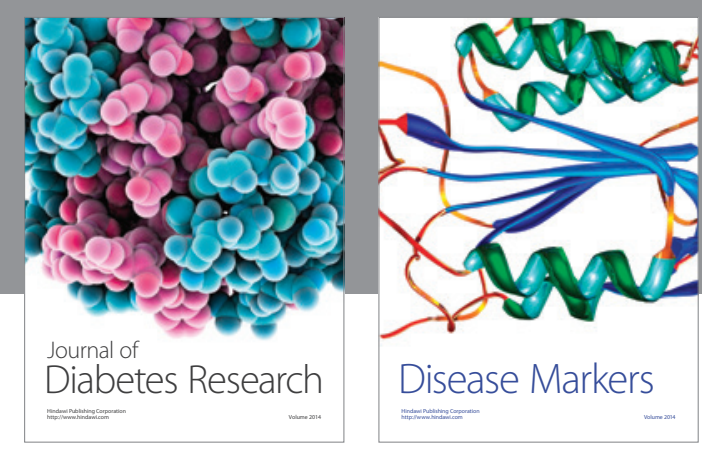

Disease Markers
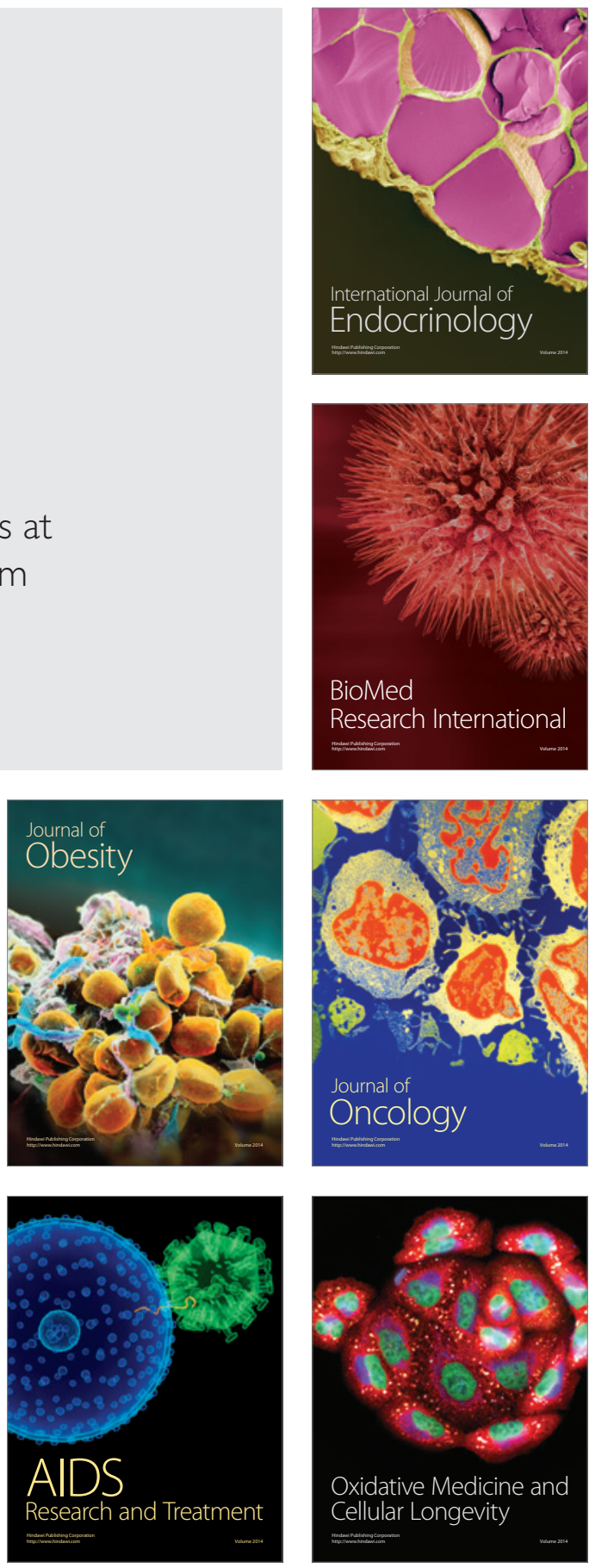